\title{
Application of contactless card reading technology for e- authentication of voters in Nigeria
}

\author{
Akonjom, Nsed A. and Ogbulezie, Julie C. \\ Dept of Physics (Electronics \& Computer Tech. Unit) University of Calabar, Calabar, Nigeria.
}

\begin{abstract}
This research work is based on introducing a very important aspect of e-electioneering into Nigerian voting system, without changing the existing laws. This is the e-authentication of voters on Election Day before voting, using the contactless card technology. This work using Poisson queuing process that is $M / G / S$ was able to show that application of contactless card reader and scanner technology for e-authentication of voters reduces the expected service time $E_{S}$ from 3 minutes to 0.75 minutes, the length of the queue from 2.25 voters to 0.044 voters and the average waiting time for voters to complete authentication reduced from 12 minutes to 1 minute.
\end{abstract}

Key words: contactless card, voters, e-authentication, card reader, election, queue

\section{Introduction}

That fragile nature of democracy in Nigeria and the unease amongst the political class is no news. Nigeria as a nation is at the brink of breaking up with the political gladiators at each other's throat, due to suspicion and counter suspicion of each other as regard rigging of election. The present method used by Independent National Electoral Commission (INEC) to carryout electioneering cannot guarantee free, fair and credible elections. This method involves only e- Registration of voters and voting is done manually on ballot paper.

This method of voting is characterized by: unreliable voter registration database file, absence of a credible voter identification system and tools, fraudulent electoral system process and inadequate appropriate voting technology (Akonjom, 2009.)

Due to these lapses the system is susceptible to abuse at both retail and wholesale level of rigging. Elections can be rigged by either or combination of two or more of the following (i) Ballot stuffing (ii) Multiply voting (iii) Inflation of figures (iv) Return of figure without voting and so on (Adesua,2010). All these form of rigging mainly occur after voting had taken place. The pre voting rigging include, but not limited to (i) Intimidation of voters (at times by scaring them with guns) (ii) Voter register list manipulation (iii) Ballot box snatching (Odirwin, 2003).

To overcome this, Nigeria as a country needs to adopt full e-voting system using available technology like the Public Network Direct Record Electronic (PNDRE). This uses electronic ballots and transmit vote and data from the polling place to another location over a public network. This method also has the capacity to accommodate internet (remote) voting.

With rigging of election threatening the present fragile nature of democracy in Nigeria and by extension the peaceful co-existence of the various geo-political region of Nigeria, it has become imperative to consider an alternative method of doing election without running fowl of the law of the land and putting the country in a more tensed situation.

The model proposed in this paper is based primarily on authenticating an individual and hence ensuring that the right person is the one casting the vote. This eliminates proxy voting; multiple voting and most importantly improve service time and consequently reduce queue length at the polls.

Nigeria has undergone many elections in its 53 years of existence and these elections have always had hitches due to improper authentication of voters and many other problems. Authentication has always been done manually and this has created many problems like manipulation by polling officials and politicians. The present method does not provide proof of voters who already voted; encourages trading of voter cards, auditing of the process is not available, multiple voting, multiple registrations and a high service time leading to long queues of voters during voting. 

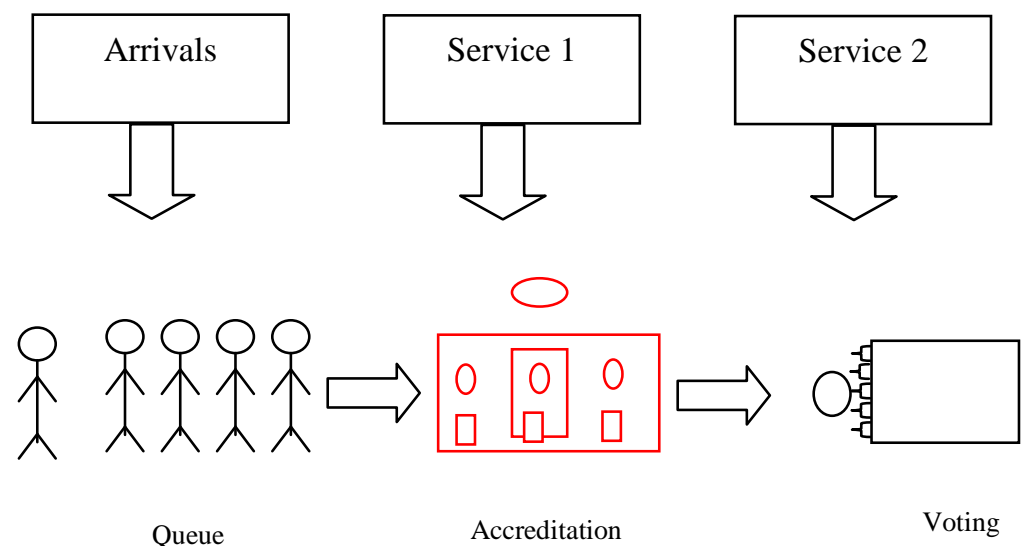

Fig 1: Three steps of the voting process in Nigeria

Congestion of polling unit (long queue) is a major hindrance affecting participation of voters in the election process. Congestion at polling unit will occur for either of two reasons (1) a line will form when service1 cannot keep pace with arrival (service1 less than arrivals). (2) a line will form when service 2 cannot keep pace with the flow of traffic into the voting booth (service2 less than arrival less than service1) as seen in Fig.1.

Long queues at polling stations lead to voter apathy therefore the need for e- authentication method. This is very fast as is it uses the contactless card reader and finger scanning technology simultaneously. This is even more necessary with the massive disadvantage the present system of voting that allows only e-Registration to be used as well as the problem associated with implementing PNDRE voting system for now, due to the prohibition of its use by the Electoral Act of the Federal republic of Nigeria Section 53(1b) (electoral act 2010, as Amended). The Law though opposed to the use of the e-voting method, does not prohibit the accreditation of voter via any means.

Introduction of e-authentication even with the use of ballot paper is as good as the entire e-voting, except for the cost associated with printing of ballot papers.

It can be implemented in three (3) ways.

1. Using a bar code reading technology: that is the scanning of individual voter card prior to voting.

2. Direct identification by placing a voter's thumb on a scanner prior to voting.

3. Using both methods simultaneously.

Both methods have their merits and demerits. But the most suitable being the direct thumb scanning, as the voters card reader is prone to abuse, since politicians in some parts of the country were known to have bought over cards from electorates and can go ahead to scan such cards and swell the votes on election dates.

The direct thumb scan will be effective, even if the register is blotted (spoofed), with factious voters as only actual voter will vote eventually. This work recommends the use of both methods simultaneously.

\section{Theoretical Background}

The research used Memory less / General/single machine (M/G/1) Queuing model theory simply explained below.

The system is in state $\mathrm{n}$, if there are $\mathrm{n}$ voters in the system. The service time is not exponential. Performance measures in steady state given: $\lambda, \mathrm{E}_{\mathrm{s}, \sigma}{ }^{2}$ here if one measure is known all measures are known.

$\mathrm{E}_{\mathrm{s}}$ is expected service time, ${ }_{\sigma}^{2}$ is variance of service time and $\lambda$ is arrival rate.

$\mathrm{L}_{\mathrm{S}}=\mathrm{L}_{\mathrm{q}}+\lambda \mathrm{E}_{\mathrm{s}}$

$\mathrm{W}_{\mathrm{s}}=\mathrm{W}_{\mathrm{q}}+\mathrm{E}_{\mathrm{s}}$

$\mathrm{L}_{\mathrm{s}}=\lambda \mathrm{W}_{\mathrm{s}}$

$\mathrm{L}_{\mathrm{q}}=\lambda \mathrm{W}_{\mathrm{q}}(\mathrm{p}-\mathrm{k})$

From Pollaczek and Kinduin formular given $\lambda, \mathrm{E}_{\mathrm{s}, \sigma}{ }^{2}$

$\mathrm{L}_{\mathrm{q}}=\frac{\lambda^{2} \sigma^{2}+\left(\lambda E_{S}\right)^{2}}{2\left(1-\lambda E_{S}\right)}$

$\mathrm{L}_{\mathrm{s}}=\mathrm{L}_{\mathrm{q}}+\lambda \mathrm{E}_{\mathrm{s}}$ 
$\mathrm{L}_{\mathrm{q}}=$ Average number of voters waiting in the queue to be served.

$\mathrm{L}_{\mathrm{s}}=$ average number of voters in the system.

$\mathrm{W}_{\mathrm{s}}=$ average time voter spends to vote.

$\mathrm{W}_{\mathrm{q}}=$ average time a voter spends in queue

M/G/1 queue is a queue model where arrivals are Markovian (modulated by Poisson process). Service time has a general distribution and this model is stochastic in nature. The state space is the set $(0,1,2,3, \ldots)$ where the value corresponds to the number of voters in the queue. The transition time from $\mathrm{i}$ to $\mathrm{i}+1$ represents the arrival of a new voter. The time between such arrivals has an exponential distribution with parameter $\lambda$. Transition from $i$ to $i-1$ represent a voter who has finished voting and left.

The length of time between arrival and service period are random variables which are assumed to be statistically independent. This work is based on the scheduling scheme of first come first served (FCFS) basis.

The queue length probability generating function of the stationary queue length distribution is given by the $\mathrm{p}-\mathrm{k}$ transform equation

$\mathrm{T}_{1}(\mathrm{z})=\frac{(1-z)(1-p) g(\lambda(1-z))}{g \lambda(1-z)-z}$

where $\mathrm{g}(\mathrm{s})$ is the Laplace transform of the service time probability density function ( Peterson ,1996). In the case of an M/G/1 queue where service time are exponentially distributed with parameter $\mu$,

$$
\mathrm{g}(\mathrm{s})=\frac{\mu}{\mu+s} \text {. }
$$

This can be solved for individual state probabilities either using direct computation or using the method of supplementary variables. The $\mathrm{p}-\mathrm{k}$ formular gives the mean queue length or mean waiting time in the system (Khintchine, 1932) and (Stewart, 2009). These are both functions of the service time. The service time required by a human for authentication of a voter is put between two and four minutes while that of the contactless card reader one hundredth of a second. Taking into account time for inserting the card into a machine and other formalities, this time can be put to about thirty seconds (Akonjom, 2013).

The busy period probability function $\varphi(s)$ can be shown to obey the Kendall function equation (Abata, 1995) and (Mitran, 1997).

$\Phi(\mathrm{s})=\mathrm{g}[\mathrm{s}+\lambda-\lambda \varphi(\mathrm{s})]$ where $\mathrm{g}$ is Laplace-Stieltjes transform of the service time distribution. For any $\mathrm{s}$, the value of $\varphi(s)$ can be calculated and by iteration with the upper and lower bands the distribution function numerically computed.

Waiting time:

If W(s) stands for the Laplace -Steiltjes transform of the waiting time distribution (Diagle, 2005)

$\mathrm{W}(\mathrm{s})=\frac{(1-) \operatorname{sg}(s)}{s-\lambda(1-g(s))}$

where $\mathrm{g}(\mathrm{s})$ is the Laplace -Steiltjes transform of service time probability density function.

\section{Materials And Method}

\subsection{Requirements}

(i) Voters card that is a Contactless smart card

(ii) Card reader, Hand held machine with two SIM cards

(iii) Printer

\section{2 contactless cards}

A contactless smart card is any pocket-sized card with embedded integrated circuit that can process and store data, and communicate with a terminal via radio wares. There are two broad categories of contactless smart cards. Memory cards contain non-volatile memory storage compounds, and perhaps some specific security logic contactless smart cards do not contain an ordinary read-only RFID, but they do contain a rewriteable smart card microchip that can be transcribed via radio wares.

A contactless smart card reader uses radio wave communication with, and both read and write data on a smart card. They come in various forms and sizes. From fixed position, example, side of entry door for security to handheld mobile devices for ticket machine and even the proposed card reader for e-authentication of voters.

The card reader/ scanner machine is expected to have

i. The card reading interface 
ii. Thumb print scanning interface

iii. Display unit for picture and thumb print images.

iv. Control card (SIM), where the customization is done and other control features that will give the reader its active nature.

v. User interface card ( SIM), that will store what have been read and help the control card to flag-up any card that have been used to avoid reuse.

vi. Printer interface

vii. Rechargeable battery that will last a minimum of 8 hours and power cords/ chargers.

Some of the features of the card reader include

(1) It should have the ability to read cards only meant for a special polling unit. Customized for Polling units ( PUs).

(2) The customization will be done on removable cards (SIM Card). This is important in case the hardware (Reader machine is faulty; we simply remove the card to another machine).

(3) The card will also have the ability to reject multiple scanning of one card for any specific election. To avoid any form of ambiguity from reinstating or initializing a card for another election day, it will be cost effective to produce several cards for the various National election days, with designated colours of the card representing each Election Day. This will save the Commission the head ache of try to modify a reader mechanism that will require a write privilege to anyone, a write privilege can be abused.

All that is needed to do is have the card replaced for each Election Day and the previous one used is kept safely for auditing of the process as well as back-up. By this therefore

(a) The card will read a card only once for that Election Day.

(b) Enable the printing of a list of voters at any time (for those who presented themselves for accreditation on Election Day).

(c) Present an audit trail after election.

(d) Save as back-up.

(e) Designated colour of card, say blue card for 1st day of election Red 2nd day of election and so on to avoid mistakes.

(4) The Reader Machine need not have the memory of voters, since it is address specific (can read cards only meant for that PU) all it needed to do is to read and store information from card of its Polling Unit, this is to help reduce cost for memory space.

(5) The card reader itself should be portable and passive in nature, with it's active nature derived from the SIM Cards that will house the control, functional and storage features. Figure 2 shows a typical contactless card.

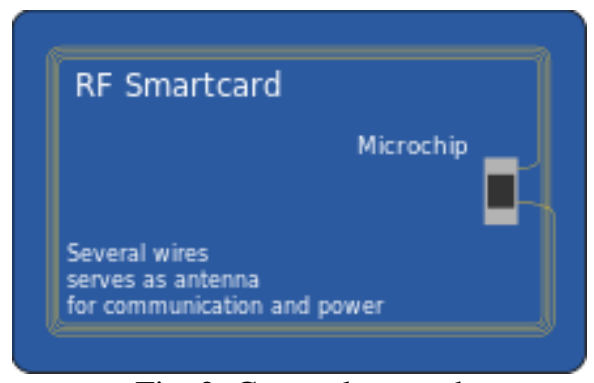

Fig. 2: Contactless card

1. Using the M/G/S (Memoriless/General/single server) System Model, where the

(i) Inter arrival time is exponential and arrival rate is Poisson process with rate $\lambda$

(ii) Service time has any distribution $\mathrm{E}$ (service) $=\mathrm{E}_{\mathrm{s}}$

When $\mathrm{E}_{\mathrm{S}}$ is known then $\mu=\frac{1}{E_{s}}$

Variance of service time $=\sigma^{2}$

(iii) Single server

(iv) System size is infinite

(v) Queue discipline $=$ FCFS $($ First Come First Served $)$ 
Therefore the notation for the entire system is $\mathrm{M} / \mathrm{G} / \mathrm{I} / \infty / \mathrm{FCFC}$

2. Apply the formular for Average number of voters waiting in line to vote Lq (Equation 5 above)

$$
L q=\frac{\lambda^{2} \sigma^{2}+\left(\lambda E_{s}\right)^{2}}{2\left(1-\lambda E_{s}\right)}
$$

And Average time a voter spends to cast his vote after arrival $\mathrm{W}_{\mathrm{s}}$

$W_{s}=\left(L q+\lambda E_{s}\right) / \lambda$

Applying the subscript $\mathrm{h}$ and $\mathrm{m}$ for human and machine operator respectively throughout this work.

3. Employing a hypothetic value of 15 voters arising per hour as arrival rate and according to (Akonjom, 2013) human operator takes between 2 and 4 minutes to carry out authentication, while the machine processes the information with one hundredth of a second. Due to human involvement in the manipulation of the machine, the transaction by machine takes between 30 seconds $(0.5 \mathrm{~min})$ to 1 minute.

\subsection{Accreditation procedure}

The flow chart of fig. 3 shows the accreditation procedure.

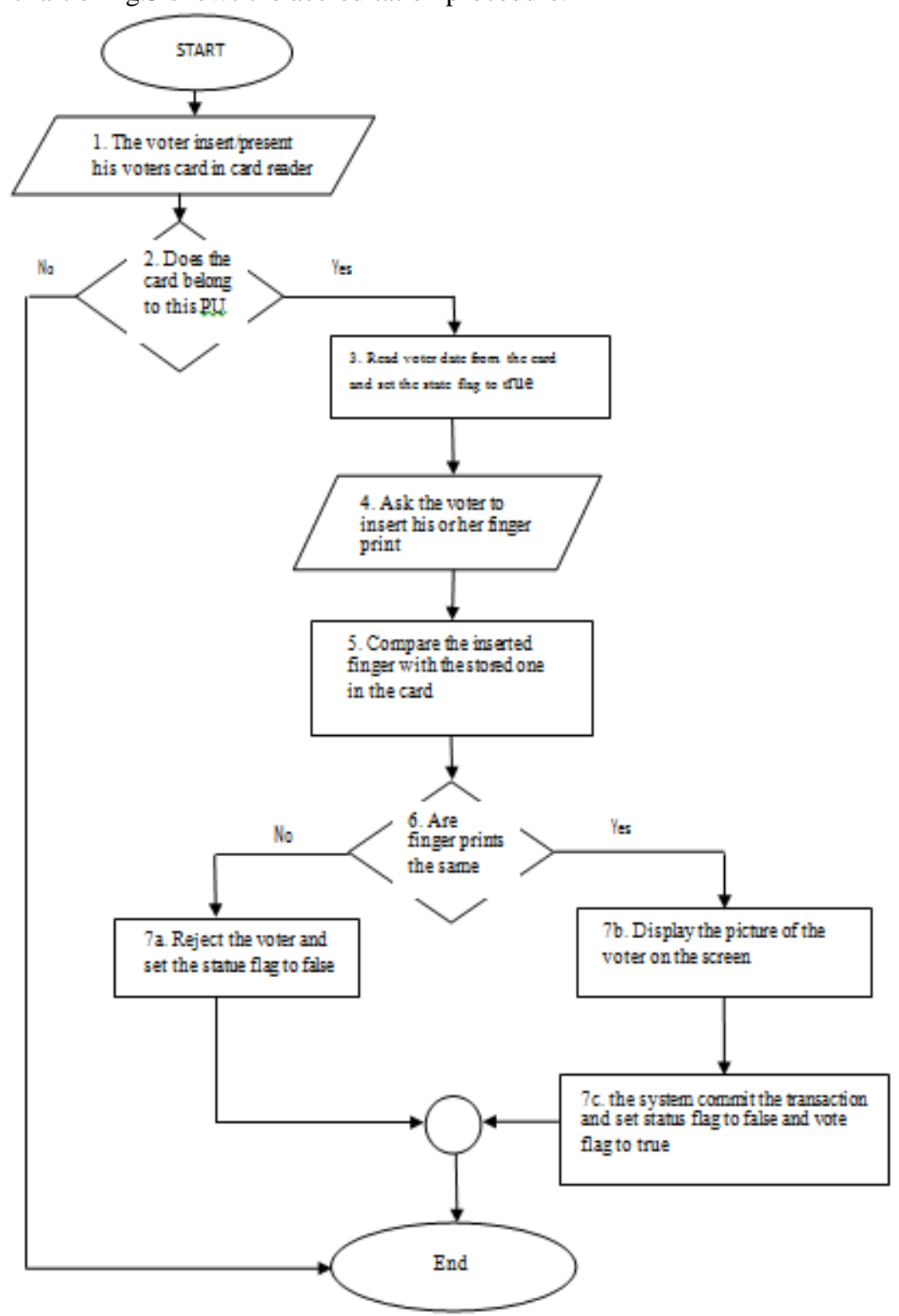

Fig.3: Flow Chart For e-Authentication Using a Smart (active) Card Reader 


\section{Results}

1. The arrival rate from the hypothetic value quoted above is 15 votes per hour. That is Arrival rate $\lambda=15$ voter per hour $=0.25$ voter $/ \mathrm{min}$

Service time for human operator $\mathrm{E}_{\mathrm{sh}}$, for carrying out Authentication is distributed evenly between $(2,4)$ minutes.

$\therefore \mathrm{E}_{\mathrm{sh}}=(2+4) / 2=3 \mathrm{~min}$.

And for machine operator, the service time distribution is between $(0.5,1)$ minute $\mathrm{E}_{\mathrm{sm}}=(0.5+1) / 2=0.75$ minutes

$$
\mu_{h}=0.333 \text { and } \mu_{m}=1.333
$$

$\therefore$

$$
\text { and } \sigma_{h}^{2}=\frac{1}{\mu_{h}^{2}}=9 \text {, while } \sigma_{m}^{2}=\frac{1}{\mu_{m}^{2}}=0.5625
$$

Average number of votes waiting in line to vote for human operator

$$
\begin{aligned}
& L_{q h}=\frac{(0.25)^{2} \times 9+(0.25 \times 3)^{2}}{2(1-0.25 \times 3)} \\
& =2.25 \text { voter } \mathrm{s} \\
& L_{q m}=\frac{(0.25)^{2} \times 0.5625+(0.25 \times 0.75)^{2}}{2(1-0.25 \times 0.7)} \\
& =0.044 \text { voter } \mathrm{s}
\end{aligned}
$$

Average time a voter spends to cast his/her vote $\mathrm{W}_{\mathrm{s}}$ for human operator.

$W_{s h}=(2.25+0.25 \times 3) \div 0.25$

$=12 \mathrm{~min}$.

$W_{s m}=(0.044+0.25 \times 0.75) \div 0.25$

$=0.926 \mathrm{~min}$.

$\approx 1 \mathrm{~min}$.

4.1 Comparison between machine and human

(1) Expected service time $\mathrm{E}_{\mathrm{s}}$

$\mathrm{E}_{\mathrm{sm}}=0.75 \mathrm{~min}, \mathrm{E}_{\mathrm{sh}}=3 \mathrm{~min}$

$\mathrm{E}_{\mathrm{sm}}$ is $25 \%$ of $\mathrm{E}_{\mathrm{sh}}$

(2) $\mathrm{L}_{\mathrm{qh}}=2.25$ voters, $\mathrm{L}_{\mathrm{qm}}=0.044$ voters

$\mathrm{L}_{\mathrm{qm}}$ is $1.96 \%$ of $\mathrm{L}_{\mathrm{qh}}$

(3) $\mathrm{W}_{\mathrm{sm}}=1$ minute $\mathrm{W}_{\mathrm{sh}}=12$ minutes

$\mathrm{W}_{\mathrm{sm}}$ is $8.33 \%$ of $\mathrm{W}_{\mathrm{sh}}$

\section{Summary}

Lines are formed when the supply of service cannot meet the demand to be served. By increasing the efficiency of the voting services, election administrators can decrease the likelihood of lines forming at polling stations during an election. 
The tradition thus far is the uses of humans at polling service one. This work looked at employing a card reader technology to improve the efficiency of accreditation (e-authentication) while service two is still the manual balloting.

Improvement at service two is mainly dependent on effective voter education and literacy levels of the voter as well as the level of simplicity applied by the election board in the way party logos (symbols) are made. This research took an in depth study on service one relying on basic assumption of queuing theory that lines form when the rate of service being provided cannot keep pace with the arrivals rate .

\section{Conclusion}

The authentication of a voter at polling station is to ensure that the bearer is the actual owner of the voter card and thus enshrining of the policy of one man one vote as required by the electoral act of Nigeria, via the use of the e-Authentication system technology which is not prohibited by law in Nigeria.

e-Authentication according to this work can be actualized using the contactless card reading technology. The work X-rayed the contactless card as well as finger print reader and talked on their merits and demerits. With an assurance that this is the way forward for our fragile democracy and the restoration of the belief of Nigerians in the Nigerian state.

\section{References}

[1]. Diagle, J.N (2005): The Basic M/G/1 Queuing system. Queuing theory with applications to packet telecommunications . pp 150223.doi ; 10.1007/0-387-22859-4_5.

[2]. Miltrani, I (1997): Queuing systems: average performance. Probalistic modeling. Cambridge University Press. Pp74-121.

[3]. Abate, J.\& Whitt, W. (1992): Solving probability transform functional equations for numerical inversion. Operators Research Letter 12(5): 275.doi 10.1016/0167-6377(92)9008-H.

[4]. Sewart, William (2009): Probability, Marcov Chains, Queues, and simulation. Princeton University Press. Pp 510.

[5]. Klintchine, A.Y. (1932): Mathematical Theory of a Stationary Queue. Mate Maticheski Sbornik 39(4): 73-84

[6]. Peterson, G.D. \& Chambelain, R.D (1996): Parallel application performance in a shared resource environment. Distributed System Engineering 3 (9).doi10.1088/0967-1846/3/1/003

[7]. Adesua S. (2010), A nation and its rigging culture. Nigerian Tribune, Tue, Aug 24

[8]. Akonjom, N .A (2009): Computer Network infrastructural Development for the Attainment of e-Election in Nigeria, Unpublished M.sc Thesis Faculty of Science University of Calabar.

[9]. Akonjom, N .A (2013): Modeling a Robust and Secure e- voting System for Nigeria Using Stochastic Process, Unpublished Ph.D Thesis Faculty of Science University of Calabar.

[10]. Cohen, B (2013), Miollions of Barclays Card Users exposedto frand. Available at http://www.channel14.com/news/millionsofbarclays-card-users-exposed-to-frand accessed on 25/11/13.

[11]. Electoral Act of The Fedeal Republic of Nigeria, 2010, As Amended Guthery, S.B. Timothy, M.J. (1998). Smart card Developer's kit. Macmillian Technical Publishing .

[12]. Hancke,G.P, A practical relay attack on ISO 14443 proximity cards. Technical report, university of Cambridge computer laboratory

[13]. Odirwin E. (2003) Rigging in Nigeria http://www.nigeriadeltacongress.com/articles/rigginginnigeria.htm Cited 20th November 2013 